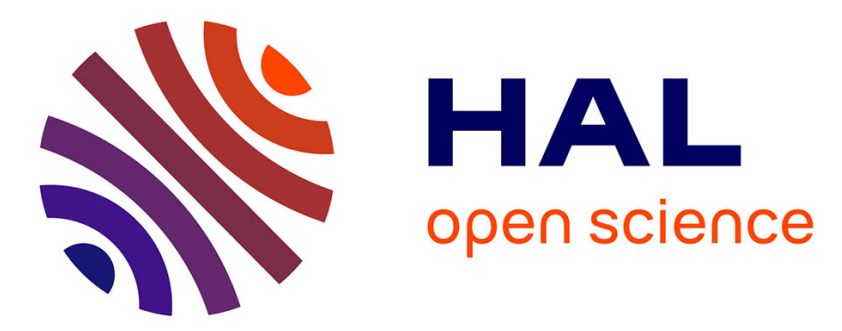

\title{
Megavolt heavy ion injector for a tandem accelerator
} E.D. Berners, C.P. Browne, P.R. Chagnon, J.W. Kaiser, W.C. Miller

\section{To cite this version:}

E.D. Berners, C.P. Browne, P.R. Chagnon, J.W. Kaiser, W.C. Miller. Megavolt heavy ion injector for a tandem accelerator. Revue de Physique Appliquée, 1977, 12 (10), pp.1407-1411. 10.1051/rphysap:0197700120100140700 . jpa-00244334

\section{HAL Id: jpa-00244334 https://hal.science/jpa-00244334}

Submitted on 1 Jan 1977

HAL is a multi-disciplinary open access archive for the deposit and dissemination of scientific research documents, whether they are published or not. The documents may come from teaching and research institutions in France or abroad, or from public or private research centers.
L'archive ouverte pluridisciplinaire HAL, est destinée au dépôt et à la diffusion de documents scientifiques de niveau recherche, publiés ou non, émanant des établissements d'enseignement et de recherche français ou étrangers, des laboratoires publics ou privés. 


\title{
MEGAVOLT HEAVY ION INJECTOR FOR A TANDEM ACCELERATOR $\left(^{*}\right)$
}

\author{
E. D. BERNERS, C. P. BROWNE, P. R. CHAGNON, \\ J. W. KAISER and W. C. MILLER \\ University of Notre Dame, College of Science, Notre Dame, Indiana 46556, U.S.A.
}

\begin{abstract}
Résumé. - On a monté, au terminal du générateur électrostatique de $\pm 4 \mathrm{MV}$ de l'Université NotreDame, une source d'ions lourds à sputtering du type 833 Hiconex. La source est munie d'une lentille Einzel à grille et d'un espace préaccélérateur qui permet la focalisation du faisceau externe. L'axe de ce groupe est décalée de $9^{\circ}$ par rapport à celui de la machine. Ainsi les atomes neutres de césium ne peuvent pas atteindre le tube accélérateur. On contrôle les conditions de fonctionnement de la source au moyen d'un télémètre à faisceau lumineux modulé à 16 canaux. On a amélioré le système de réglage de tension accélératrice, qui contrôle le courant de courroi aussi bien que la tension du liner du tank. Nous avons un nouveau circuit de voltmètre générateur qui n'est sujet à aucune limite essentielle en fréquence. L'analyse, magnétique et électrostatique, du faisceau négatif accéléré permet une résolution de masse de $1,4 \%$ (mesurée) et d'énergie de $0,1 \%$ (calculée). Une ligne de $34 \mathrm{~m}$ qui fait un angle de $123^{\circ}$ porte ce faisceau à l'entrée du Tandem FN, au moyen de déflection et de focalisation électrostatiques. Aux premiers essais, on a obtenu $4 \mu \mathrm{A}$ analysé de ${ }^{12} \mathrm{C}$. On a mesuré aussi $50 \mathrm{nA}$ de ${ }^{11} \mathrm{~B}$, entièrement séparés du faisceau de ${ }^{10} \mathrm{~B}$ et de ${ }^{12} \mathrm{C}$.
\end{abstract}

\begin{abstract}
A sputter ion source, Hiconex Model 833, is mounted in the terminal of the NotreDame $\pm 4 \mathrm{MV}$ electrostatic accelerator. The terminal contains a gridded einzel lens, an accelerating gap for external beam focus, and a $9^{\circ}$ electrostatic deflector which prevents neutral caesium atoms from reaching the accelerating tube. Source parameters are observed through a 16 channel modulated light beam telemetry system. The existing terminal voltage stabilizing system which controls belt charge and tank liner voltage was modified for improved response to the generating voltmeter. A new generating voltmeter circuit which has no inherent frequency limitation has been developed and is functionning. Magnetic and electrostatic analysis of the accelerated negative ion beam provide mass resolution of $1.4 \%$ (measured) and energy resolution of $0.1 \%$ (calculated). Electrostatic steering and focusing elements transport the analyzed beam through 34 meters and a $123^{\circ}$ deflection for injection into an FN Tandem. In early testing at $2 \mathrm{MeV}$, an analyzed beam of $4 \mu \mathrm{A}$ of ${ }^{12} \mathrm{C}$ was obtained. We have also measured $50 \mathrm{nA}$ of ${ }^{11} \mathrm{~B}$, completely resolved from the ${ }^{10} \mathrm{~B}$ component and also from a large ${ }^{12} \mathrm{C}$ contaminant beam.
\end{abstract}

The Nuclear Structure Laboratory at the University of Notre-Dame operates an FN Tandem Van de Graaff installed in 1968, and a single-ended \pm 4 MV electrostatic accelerator built by the Notre-Dame Physics Department in 1954.

The 4 MV machine was built originally to accelerate electrons, and was converted in 1956 to bipolar operation to provide positive ion beams as well. The Tandem laboratory was laid out in such a way that conversion of the $4 \mathrm{MV}$ machine into a negative ion injector would be possible, and the development of the Middleton sputter source made this possibility quite attractive.

With 3-stage operation we hoped to be stripping at $12-13 \mathrm{MeV}$ instead of 8-9 MeV. For heavy ion beams the increase in stripping energy was expected to increase the useful charge state by one to two units. We thus could expect an increase in useful energy of

$\left(^{*}\right)$ Work supported by the National Science Foundation under Grant No. PHY76 23352.
12 to $20 \mathrm{MeV}$, or an increase in useful current at lower energies.

Another important advantage to be gained was greatly improved transmission through the Tandem. (Our transport calculations predicted $100 \%$ transmission.) We expected that loading of the tube by the beam would be smaller, and that tube damage would be less likely than with low energy injection.

We have attempted to provide these features:

1) good optical matching of the source to the accelerating tube of the injector,

2) reasonable assurance that the accelerating tube of the injector would not become coated with caesium,

3) efficient beam transport to and through the Tandem,

4) minimum losses through charge-changing in the vacuum,

5) some mass analysis before injection,

6) stable operation,

7) protection against radiation hazards,

8) low cost. 
The terminal source installation is shown in figure 1. The source (1) is a Hiconex [1] Model 833. Negative ions produced at the sputter cone (2) by positive caesium ion bombardment are accelerated to ion source ground potential. A gridded einzel lens (3) focuses the ion beam through an accelerating gap (4) which matches the ion energy to the accelerating tube gradient.

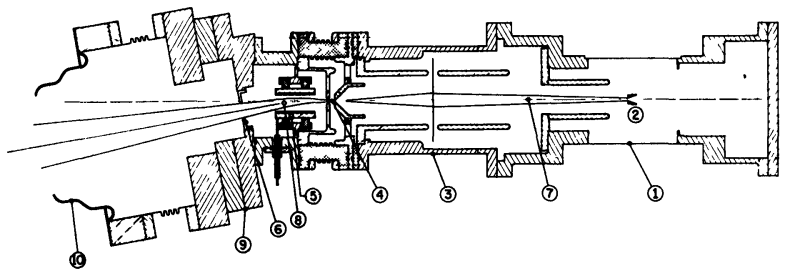

FIG. 1. - Terminal source installation. (1) Source, (2) cone (3) einzel lens, (4) focus gap, (5) steering plate, (6) aperture, (7) and (8) magnetic electron suppression, (9) gate valve, (10) tube electrode. Internal details of the sputter source are not shown.

The source and lens axis is tilted $9^{\circ}$ from the accelerating tube axis. Electrostatic steering plates (5) deflect the negative ion beam onto the tube axis; any neutral caesium atoms coming from the source are not deflected and are stopped by an aperture (6).

The sputter source emits a large electron current which would severely load the accelerator charging system if it were not suppressed. We have provided magnetic fields for electron suppression at the extraction electrode (7) and at the steering plates (8). In addition, the final aperture (6) before the tube is insulated from ground and connected to the positive steering plate. The magnitude of the steering voltage is always sufficient to trap the most energetic secondaries produced at the aperture.

A remotely operated gate valve (9) is provided to isolate the source from the tube (10).

Cooling for the sputter cone and the cesium reservoir are provided by circulating accelerator insulating gas. A compressor outside the tank takes in gas from the accelerator tank and discharges it at a pressure 1.3 to $2 \mathrm{~kg} / \mathrm{cm}^{2}$ above tank pressure. The higher pressure gas is piped into the tank and flows to the terminal through $6 \mathrm{~mm}$ O.D. polyethylene tubing lying on the column gradient bars. The flow required is about $80 \mathrm{l} / \mathrm{min}$. The warm gas is dumped into the tank and eventually recycled.

The quick cool system for the cesium reservoir uses distilled water which also is pumped to the terminal through polyethylene tubing, then returned to a container outside the tank. After using water, the tubing is purged with dry air for two hours before voltage is applied.

There are two systems for monitoring source parameters. For many years we have had a TV camera viewing meters in the terminal through a window in the tank. In 1976 we installed a 16 channel telemeter which sends information from the terminal to the control room by a pulse modulated light beam.

All signals going to the light beam telemeter are first converted to DC voltages between 0 and 5 volts. These DC levels go through an analog multiplexer to the voltage-to-frequency converter, which generates pulse trains of 0 to $100 \mathrm{kHz}$. These 16 frequencies and the pulses for timing and channel identification are assembled into proper sequence by the logic system. The pulse train is transmitted to ground potential by a high-intensity narrow-beam LED.

A photo diode outside the tank detects the light signal. Amplified pulses are sorted, counted, and stored in memory. Each channel has a 2-digit LED display and an analog meter display. We expected the two display modes to complement each other, but in operation we only notice the digits.

Signals are brought to both terminal metering systems through coaxial cables made of teflon insulated wire in $3 \mathrm{~mm}$ O.D. copper tubing. Figure 2 shows how surge suppression is used at the signal pick-off

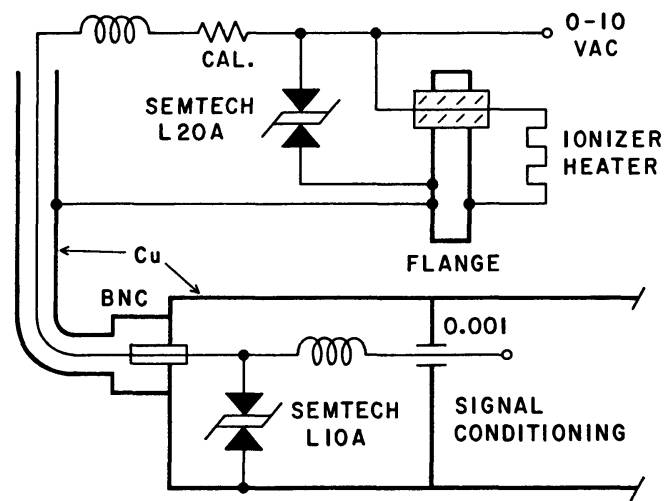

FIG. 2. - Telemeter input circuit for ionizer heater channel, with typical surge suppression.

point and at the entrance to the shielded metering enclosures. The surge suppressors are a commercial item [2]. The particular channel shown is the only one to have failed in use. The resistor marked CAL. increased greatly in value and reduced the signal essentially to zero. It is mystifying that this failure occurred while the terminal was grounded by the radiation safety interlock. However, since the resistor was not in any shielded enclosure, we still consider the surge protection to be successful. The telemeter system has run for 400 hours and survived terminal sparks up to $3 \mathrm{MV}$.

We have made several changes in the stabilizing system of the injector. A new generating voltmeter circuit which has no inherent frequency limitation has been developed and is functioning. As shown in figure 3, two sets of stator plates are connected to matched charge sensitive amplifiers. $A(t)$ is the fraction of each stator plate area that is exposed to the electric field, i.e., not shielded by the rotor. As the rotor turns, $A(t)$ changes, and the induced charge is a quasitriangular function of time. However, the sum $A_{1}(t)+A_{2}(t)$ 

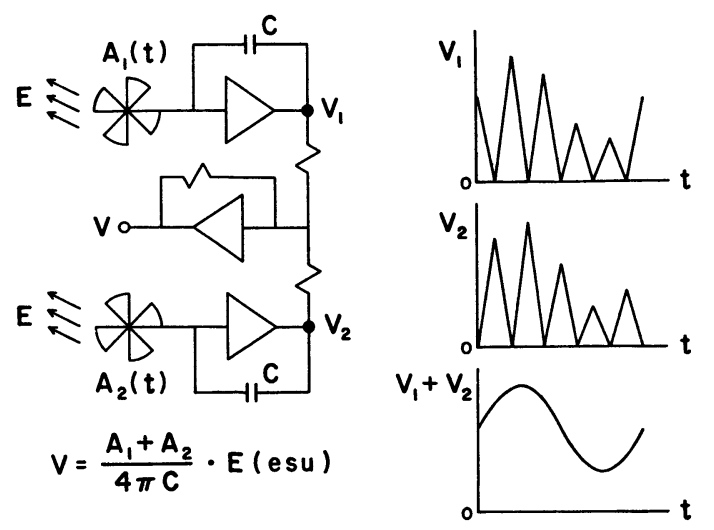

FIG. 3. - The generating voltmeter. Left, the amplifier circuit. Right, its waveforms, assuming a sinusoidal terminal ripple.

remains constant. The sum $V$ of the two charge signals depends only on the electric field at the plates and the total exposed stator area :

$$
V=\frac{\left(A_{1}+A_{2}\right)}{4 \pi C} \cdot \varepsilon E \quad(\mathrm{esu})
$$

The stabilizer circuit derives its error signal from the generating voltmeter, from the image slits of the energy and momentum analysis system, or from a combination of both. Transfer of control from generating voltmeter signal to slit signal is automatic.

The output to the accelerator proceeds through two branches: the low frequencies control the upcharge current, while higher frequencies go to an insulated tank liner which is driven up and down in voltage. That component of the generating voltmeter signal due to the electric field produced by the tank liner is cancelled out in the generating voltmeter circuit.

A feature of the stabilizer which is particularly suited to the anticipated semi-automatic operation of the injector is that the rate of rise of terminal voltage is limited to a pre-programmed value.

Since we wanted to use the existing analyzing magnet to provide some mass separation, the optical matching of source to accelerating tube had to provide that the beam could be focused at the object slits, and that it would pass through the $12.5 \mathrm{~mm}$ gap between the magnet poles.

The value of $Q$, the ratio of ion energy after acceleration to ion energy at the entrance to the accelerating tube gradient, determines the focal length of the accelerating tube. This value and the location of the image point require a particular object .point and magnification for the tube.

A suitable object point and $Q$ value were determined experimentally using the positive ion beam from an $r$. f. source. By shorting out one or more sections of accelerating tube, the source could be moved away from the tube in steps of $62 \mathrm{~mm}$. In the configuration chosen, the focus gap ((4) of Fig. 1), which is the object, is $38 \mathrm{~cm}$ from the tube entrance, and $Q$ is 90 .
The first four tube sections operate at half the normal voltage gradient.

Using data obtained by High Voltage Engineering Corporation ( 1 ) for a tube similar to ours, and the guaranteed emittance of the source, we then could estimate that the magnification of the einzel lens should be 0.5 , the tube magnification would be about 3 , and the beam divergence after the object slits would be 1.25 milliradian at an energy of $4 \mathrm{MeV}$.

Figure 4 shows the laboratory plan with both accelerators and the injection beam line. The beam from the injector, after leaving the object slits, goes through a $6^{\circ}$ magnetic deflection and a $27^{\circ}$ electrostatic deflection and is brought to a horizontal focus at

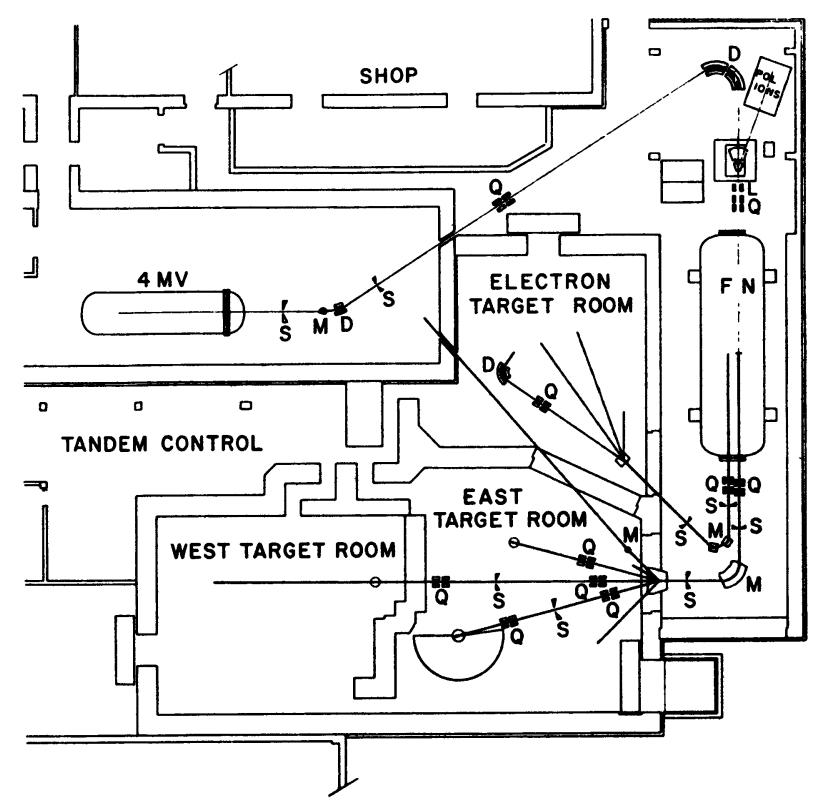

FIG. 4. - Experimental area in the Nuclear Structure Laboratory at the University of Notre-Dame.

the image slits. The beam then drifts to an electrostatic quadrupole doublet which forms a waist $10 \mathrm{~cm}$ in front of a second electrostatic deflector. The second deflector consists of two sections, each producing a deflection of $61.5^{\circ}$. A horizontal waist is formed between the two sections, and another is formed $10 \mathrm{~cm}$ after the end of the deflection. A second electrostatic quadrupole doublet forms a waist at the Tandem stripper. The distance from object slits to Tandem tank base is $\mathbf{3 9 . 6}$ meters.

Table I gives the beam dimensions from ion source to Tandem stripper. The values were obtained with a first order optics program, neglecting scattering, space charge, and aberrations.

All of the optical elements described were designed and built in our laboratory. The quadrupole doublets have an aperture of $5 \mathrm{~cm}$ and can focus $4 \mathrm{MeV}$ ions at

(1) Private communication from Ch. Goldie. 
TABLE I

Calculated beam half-widths at $4 \mathrm{MeV}$

\begin{tabular}{|c|c|c|c|}
\hline Element & $z(\mathrm{~m})$ & $x(\mathrm{~mm})$ & $y(\mathrm{~mm})$ \\
\hline Sputter cone & 0.00 & 1.6 & 1.6 \\
\hline Focus gap & 0.38 & 0.8 & 0.8 \\
\hline Tube entrance & 0.76 & 23.6 & 23.6 \\
\hline Object slit & 8.2 & 2.5 & 2.5 \\
\hline Image slit & 13.9 & 2.2 & 10.6 \\
\hline Quadrupole & 22.8 & 25.4 & 19.8 \\
\hline \multicolumn{4}{|l|}{ Deflector: } \\
\hline Entrance waist & 37.0 & 1.6 & 2.0 \\
\hline Center waist & 38.4 & 1.6 & 3.7 \\
\hline Exit waist & 39.8 & 1.6 & 5.5 \\
\hline Quadrupole & 46.1 & 12.4 & 13.4 \\
\hline Stripper* & 53.8 & 2.0 & 2.0 \\
\hline
\end{tabular}

$\left.{ }^{*}\right)$ With Tandem terminal voltage equal to zero.

$\pm 10 \mathrm{kV}$. The electrostatic deflectors use cylindrical deflecting plates with mean radius of $122 \mathrm{~cm}$ and $1 \mathrm{~cm}$ gap. They will bend $4 \mathrm{MeV}$ ions at $\pm 34 \mathrm{kV}$, and have been tested successfully at that voltage. The same high voltage supplies are used for both deflectors. The $6^{\circ}$ magnet can deflect negative ions with $\mathrm{M}=225$ at $4 \mathrm{MeV}$.

Momentum and energy analysis are provided by the magnet and first electrostatic deflector. The resolution predicted at $4 \mathrm{MeV}$ is 0.02 in mass and 0.001 in energy. Beam diagnostic equipment includes four Faraday cups with secondary electron suppression, and five scanners.

Losses of negative ion beam current through interactions with the residual gas were estimated using the results of Wegner and Thieberger. [3] At $10^{-7}$ torr average pressure the stripping losses for $\mathrm{OH}^{-}$would be $1 \%$, and that value was adopted as a design parameter.

The beam line is constructed of aluminium alloy 6061, solvent cleaned, air baked, and Viton sealed. Gate valves also are aluminium. In a compromise among conflicting requirements of conductance, cost, and convenience, we chose pipe of $10 \mathrm{~cm}$ inside diameter pumped by five conventional ion pumps [4] rated at $100 \mathrm{l} / \mathrm{s}$ each. The average length of beam line pumped by each pump is 8 meters.

A test section of beam pipe was set up using one pump, a valve, and typical plumbing but with no optical elements. This section after baking under vacuum at $125{ }^{\circ} \mathrm{C}$ reached an average pressure of $6 \times 10^{-8}$ torr. In the actual beam line, the best average pressure reached so far for the entire line is $2 \times 10^{-7}$ torr.

The pressure in the $4 \mathrm{MV}$ accelerating tube has not been that low. Typical values with the source turned on are 1-2 $\times 10^{-6}$ torr at the ground end of the tube and an estimated 5 or 10 times higher at the terminal end. The pressure in the source is probably always above $10^{-5}$ torr. We plan to, install a terminal pump.
One of the problems caused by the poor tube vacuum is a high radiation level when the machine is running. Although electrons from the source are trapped in the terminal, the radiation we observe suggests that a considerable electron beam is being accelerated. We believe the electrons are being stripped from negative ions by the residual gas in the accelerating tube. To alleviate the radiation hazard we have installed in the tank a motor-driven grounding arm which must be in contact with the terminal before the gate to the accelerator room can be opened.

The injector project was undertaken at a time when operating funds were being cut back and special project grants unobtainable. It was necessary to minimize costs in many ways, but the choice of cylindrical electrostatic deflectors instead of bending magnets for the $123^{\circ}$ and $27^{\circ}$ deflections was most important, since the cost of the magnets would have been prohibitively high. The cost of the project to date is $\$ 41,000$, including $\$ 17,500$ for the ion source. In addition, the project required 1100 hours of shop time. Shop support was budgeted and would have been paid out anyway, injector or no.

We would like to emphasize the advantages to be gained by using electrostatic fields for large deflections and for energy analysis of negative ion beams. Heavy ion injectors for Tandems are operating in the megavolt range and $M E Q^{-2}$ exceeds $10^{3}$. If the injector is built in a vertical configuration or if space limitations apply, deflections of $\sim 90^{\circ}$ may be necessary. To do this with a magnet means that it must be either enormous or superconducting. Compared to these, the cylindrical electrostatic deflector/analyzer is a modest undertaking.

One should certainly consider buying just enough magnet to provide the desired mass dispersion and doing the rest of the deflection electrostatically. Such a combination may be only weakly focusing in the direction transverse to the deflection, but an electrostatic quadrupole could be added. 
The injector beam line was completed in February 1977, but we have been able to measure its performance only since early May, when additional Faraday cups were installed. Cups are located after the object slits, after the image slits, at the entrance to the $123^{\circ}$ deflector, and after the $123^{\circ}$ deflector. The best value we have observed so far for transmission from the image slits of the injector to the Tandem ion source box is $73 \%$. We expect this value to be better in the future as the vacuum in the new beam line improves. The transmission measurements were made just after the entire line was opened to install Faraday cups, and the pressure was still $2 \times 10^{-6}$ torr. The calculated beam loss [3] due to stripping at this pressure is $17 \%$, which is a large part of the observed loss.

Also in May 1977, the first experiment using the 3-stage beam was performed. For this run the injector was at 2.26 MV and the Tandem at 9.0 MV, giving
83.26 MeV $160^{8+}$ ions at the target. The analyzed $8+$ beam current was $20 \mathrm{nA}$, and in this case was more than the experimenter wanted. The injected negative ion current was $0.40 \mu \mathrm{A}$, and the total current in all charge states after acceleration through the Tandem was $2.6 \mu \mathrm{A}$. Published values [5] of average charge states after stripping would indicate that the particle transmission through the Tandem during this run was greater than $100 \%$. This unlikely result may be due to incomplete suppression of secondary electrons leaving the Faraday cups. In all of our 3-stage runs, the transmission calculated in the same fashion has varied between $83 \%$ and $110 \%$.

A few other test results can be mentioned, although they are very preliminary, and at much less than the $4 \mathrm{MeV}$ ion energy for which the transport calculations were done. Table II lists results with the two ion beams used in most of our testing so far.

TABLE II

Beam currents in the 3-stage accelerator at $2.27 \mathrm{MeV}$ injection energy

\begin{tabular}{|c|c|c|c|c|c|c|}
\hline Ion & $\begin{array}{c}\text { Object } \\
\text { slits } \\
(\mathrm{nA})\end{array}$ & $\begin{array}{l}\text { Image } \\
\text { slits } \\
(\mathrm{nA})\end{array}$ & $\begin{array}{c}\text { Injected } \\
\text { current } \\
\text { (nA) }\end{array}$ & $\begin{array}{c}\text { Tandem } \\
\text { terminal } \\
(\mathrm{MV})\end{array}$ & $\begin{array}{c}\text { Ótput } \\
\text { current } \\
\text { (nA) }\end{array}$ & $\begin{array}{c}\text { Charge } \\
\text { state }\end{array}$ \\
\hline - & - & - & - & - & - & - \\
\hline${ }^{12} \mathrm{C}$ & 9600 & 2800 & 1400 & 8.0 & 6400 & - all \\
\hline${ }^{16} \mathrm{O}$ & 1300 & 700 & $\begin{array}{l}440 \\
410\end{array}$ & $\begin{array}{l}0.0 \\
8.5 \\
8.5 \\
8.5\end{array}$ & $\begin{array}{r}250 \\
2100 \\
200 \\
8\end{array}$ & $\begin{array}{l}-1 \\
\text { all } \\
+7 \\
+8\end{array}$ \\
\hline
\end{tabular}

In the future we expect to cure the sparking problems which have appeared in the injector since its long period of idleness during the conversion. Operation at full energy ought to improve transmission all the way through. We expect also to get more output from the source, since 1) we will be able to use higher extraction voltage, and 2) we have been keeping the cesium ion current to $2 \mathrm{~mA}$ or less. There are many more ion species to be tried, and we hope that terminal pumping will make it more feasible to use gas spray on the sputter cones to enhance the yield of certain ions. Finally, tuning the injection transport system is a complex operation and we expect the transmission to improve as we gain more experience.

Acknowledgements. - The authors gratefully acknowledge the valuable assistance of $\mathbf{C}$. Guy in all phases of the project, $\mathrm{G}$. Marolt in the terminal source installation, A. Visvanathan in the beam line construction, D. McLane and J. Lonie with the electronics, and N. Nash who prepared the drawings for this paper. We thank A. Horvath and F. Rzeszutek of the department machine shop for their expert and careful work in the manufacture of all components of the beam transport system.

\section{References}

[1] General Ionex Corporation, Ipswich, Massachusetts.

[2] Semtech Corporation, Newbury Park, California.

[3] Wegner H. E. and Thieberger P., Nucl. Instrum. Methods 122 (1974) 287-289.

[4] Perkin-Elmer Ultek, Inc., Palo Alto, California.

15] Bоoth W. and Grant I. S., Nucl. Phys. 63 (1965) 481-495. 